\title{
HARNESSING THE MEDICINAL POTENTIAL OF SELECTED FRUIT AND VEGETABLE WASTE AGAINST GRAM POSITIVE BACTERIA
}

\author{
Geodilyn B. Buan ${ }^{1 *}$, Krystel Grace Vergara Padilla ${ }^{1}$, Danny O. Alfonso ${ }^{1^{*}}$ \\ ${ }^{1 *}$ College of Arts and Sciences, Nueva Ecija University of Science and Technology, \\ Cabanatuan City, Nueva Ecija, 3100, Philippines;
}

"Corresponding Author Danny O. Alfonso, e-mail: danofiaza20@gmail.com;

Received December 2020; Accepted January 2021; Published February 2021;

DOI: https://doi.org/10.31407/ijees11.119

\begin{abstract}
Many fruits and vegetables are being thrown in the garbage because some believed that these were just rubbish, but nowadays, fruits and vegetables may not be considered wastes anymore. Fruit and vegetables peel is known to be agro-waste, which is discarded into the environment. Instead of being used as a source of antimicrobials, environmentalists and researchers found ways on the antibacterial potential of some fruits and vegetable peels. The presence of important components that can be used for pharmacological or therapeutic purposes has also been discovered by unique peel studies. This study employed a quasi-experimental design (QED) in selected fruits and vegetables waste peel of Cabanatuan City Public Market to determine their antibacterial potential against Staphylococcus aureus ATTC 25923. Ethanolic extracts were tested for the antibacterial screening using disk diffusion assay. Visual assessment was used for the results of antibacterial potential such as the presence or absence of clear inhibition or halo around the paper disc. The results showed that peel extracts of Musa acuminate L., Dimocarpus longan L., Ananas comosus L., Carica papaya L., Citrus reticula L., and Allium cepa L. exhibited inhibitory growth against Staphylococcus aureus ATTC 25923 while Ipomoea batatas L., Cucurbita maxima D., Luffa cylindrical, and Moringa oleifera L. did not show antibacterial potential against S. aureus ATTC 25923. Therefore, this study can definitely open up as a scope for future utilization of the waste for therapeutic purpose.
\end{abstract}

Keywords: Antibacterial Screening, Staphylococcus aureus, Fruits and Vegetables Waste, disk diffusion assay, Antibiotic Resistance 